Research Article

\title{
Facility Maintenance Traceability Information Coding in BIM-Based Facility Repair Platform
}

\author{
Nai-Hsin Pan $\mathbb{D D}^{1}$ and Kuei-Yen Chen ${ }^{2}$ \\ ${ }^{1}$ Department of Civil and Construction Engineering, National Yunlin University of Science and Technology, Douliu, China \\ ${ }^{2}$ Graduate School of Engineering Science and Technology, National Yunlin University of Science and Technology, Douliu, China
}

Correspondence should be addressed to Nai-Hsin Pan; pannh@gemail.yuntech.edu.tw

Received 27 October 2019; Revised 23 February 2020; Accepted 9 May 2020; Published 8 August 2020

Academic Editor: Heap-Yih (John) Chong

Copyright (C) 2020 Nai-Hsin Pan and Kuei-Yen Chen. This is an open access article distributed under the Creative Commons Attribution License, which permits unrestricted use, distribution, and reproduction in any medium, provided the original work is properly cited.

\begin{abstract}
The importance of facility management (FM) has gradually been recognized in the life cycle of a building. Both new and existing buildings require a more efficient approach and advanced technology to improve the efficiency of the FM. The study is aimed to enhance the facility repair process. Thus, the study presents a building information modeling (BIM)-based facility repair platform framework, which enables expedited reporting for repairs and a comprehensive listing of the status, location, and maintenance record facilities. To effectively facilitate the FM information transfer among stakeholders, firstly, the study presents a facility traceability coding structure for building facilities, the proposed platform framework. The proposed facility traceability information coding in QR code format can help general users and FM personnel identify and locate the specific or abnormal facility quickly. Secondly, the study demonstrates that how to apply the proposed code in QR code format in the BIM-based facility repair platform with a case test. The research findings showed that the proposed method enables FM personnel to significantly improve the efficiency of FM, which can help FM personnel make preliminary facility repair judgments and schedule maintenance plan to track the status of the facility repair which can help improve the efficiency of facility management and simplify the repair process.
\end{abstract}

\section{Introduction}

Facility management (FM) has been increasingly important during the life cycle of buildings. Proper policies and advanced technologies are needed to enhance the efficiency of FM for new and existing buildings. At present, great progress has been achieved in the applications of BIM in construction engineering-related fields and models are established rapidly. BIM provides not only three-dimensional (3D) modeling but also detailed building information. BIM can show the appearance of buildings after completion, but the provided information is widely used in the fields, such as budgeting, procurement management, project scheduling, abnormal status detection, maintenance, and management. BIM generates the building's information which has made great contributions to the development of construction engineering and FM. Proper maintenance management is one of the key factors to extend the life cycle of buildings. As time goes on, deterioration will reduce buildings' functions and values, and severe problems may arise if prompt repair and renovation is not conducted. Integrating BIM into FM can effectively restore the deteriorated facilities, so that buildings' functions and values can be maintained for a long period. By supporting 3D visual management and providing relatively correct information, BIM could help work more efficiently. In early time, information management is conducted manually with paperwork, which is inefficient. At present, BIM brings great efficiency to related operations and data storage. Using computerized information management and database technology, data are transmitted to the platforms and are made accessible to general users. Users can also easily examine and view the maintenance records of the registered amenities in BIM systems. With minimal technical restrictions, more users are able to implement BIM. As BIM is applicable in all stages of the life cycle of buildings, its facility 
maintenance management and multiple active effects have been widely researched. It is well known that facility management (FM) products using BIM technology are released in many software applications, but these products are often less useful than expected. As a result, relevant studies were investigated in this study to explore the potential applications of FM and BIM from another perspective.

At present, BIM is applied within the scope of FM. In the FM industry, stakeholders have not fully used BIM and the FM programs which apply BIM now, most operations are still completed manually, and facility management can reduce the possibility of errors and improve efficiency by implementing BIM during construction [1, 2]. Errors in facility management will increase continuous problems such as unregistered property, property irrelevant to the government, defects in maintenance, property not being utilized, and property misappropriation [3, 4]. In fact, BIM provides great effects on FM of building projects [5], involving owners and FM staff. It is well known that the applications of BIM in FM concern various practices, including people, locations, processes, and technologies, to ensure higher performance in the actual building environment. Basically, BIM is primarily for the use phase. By allowing the generating and acquisition of facility information throughout buildings' life cycle, the commercially accessible technologies can transfer information among building life cycle phases. Computerized supports are required to improve the way to manage facilities [6]. The requirements in FM must be obvious to get the attention on BIM applications. FM-related organizations have provided the possibility of using BIM (such as knowledge acquisition) to record the constantly changing facility information and of helping facility managers to make decisions throughout the operation period of facilities. BIM also can improve the living quality in workplaces, but the ability to resist changes is the difference in thought, motivation, plan, or goal related to five fields: necessity of reform, risks, goals and objectives, leaders, and cure of conditions [7]. Liu clarified the maintainability problems which frequently occur and studied the potential areas where BIM can be used to solve problems in maintenance in the early stage of design [8].

$\mathrm{Kim}$ et al. incorporated mobile systems and BIM into facility management, allowing engineers to manage facilities [4]. BIM is integrated into systems, which provides detailed visual information of building components. Lee et al. presented a multiagent system which can trace the status of facilities' data. In the area of facility management, some studies attempted to use the three-dimensional visualization technology to describe the facilities focusing on facility management, for instance, the space navigation systems that have been used in cities, museums, and campuses [9]. Mozaffari et al. provided three-dimensional CAD models for the affiliated building facilities by using VR [10]. Chen et al. proposed the expert system models for maintenance management of buildings in the form of 3D facility models [11]. The research developed database schemas to enhance the decisions during maintenance. In the as-built BIM models, all parts of the layout may involve geometric information (dimensionality and locations) or semantic information (e.g., serial number, product data, maintenance manual, and assurance data). As-built models are important in the successful use of BIM at O\&M phases of buildings and civil infrastructure. It is recognized that BIM contributes to the advantages and demands of building maintenance [12]. McArthur presented a BIM model which used case studies to prove that it is difficult to use BIM models for building operation, maintenance, and durability. In addition, some studies focus on using innovative technologies for maintenance management. For example, BIM and geographic information system (GIS) can enhance railway maintenance and operation [13]. Kang and Hong proposed a software architecture which is used to effectively integrate building information modeling (BIM) into the FM systems based on the geographic information system (GIS) [14]. Some studies are related to decision supports of facility maintenance. Motamedi provided visualization for FM with the visualization function of BIM, so that they can solve problems by using their cognitive and perceptual reasoning. Motamedi provided a visualization analysis based on knowledge support and BIM to detect the primary causes of failures in FM [7]. Based on the above, most studies have already recognized the importance that using BIM or BIM integrated with some information technologies can enhance the efficiency of FM. However, from the viewpoints of FM personnel, how to apply BIM in FM for the practical use purposes has not often been explored.

Also, to effectively manage quality, risk management, and cost, each component of a 3D model should be assigned an individual ID in the computer [15-17]. In the USA, a standard was developed by the US Army Corps of Engineers called Construction Operations Building Information Exchange (COBie). Its concept is mainly to collect information at the planning and design stage at the beginning of a project. During the construction of the project, building materials have been created. For example, designers can provide space, floors, and layouts. Subcontractors can provide information such as equipment models. With the relevant information provided by each unit in each stage, it is standardized into a format, which can be delivered directly to this standard when the final project is completed, which saves the time for the facility operating unit to integrate the data and greatly improves its efficiency [18]. Research findings reveal that further development of COBie is required to mitigate software inflexibility and augment automation of semantic data transfer, storage, and analysis. Zhang and Dong propose an EBS standard that embodies a coding system for highways and at the same time meets the requirements of BIM management, project management (PM), and operation management (OM) in life cycle management process. This paper presents an EBS standard based on three classifications: (1) project-level construction, (2) project-level operation, and (3) network-level operation [19]. Therefore, to fully take the benefits of BIM in FM, an efficient information exchange approach is needed among a building project's stakeholders. Based on the related literature review, some state-of-the-art technology has been explored the feasibility of FM. Also, there is some commercial software of FM utilized in the real world. However, there is lack of 
investigating the significance of coding of FM traceability information and how to integrate FM traceability coding information in BIM-based facility repair process. After the building project is completed and delivered to the owner, coding each facility classification information of the building has significant benefits for the operation management. The facilities in the building with unique standardized code can be identified, and the information storage and sorted can be managed electronically instead of paper-based data processing that requires a large amount of manpower traditionally. Furthermore, the implementation of standard codes can carry out the information of facility traceability during the phase of design and construction. Once the information of the facility needs to be queried, the independent and unique coded facility history information is directly extracted from the system's database. This study aimed at proposing a BIM-based facility repair platform framework which can accelerate repair reports and fully list the status, locations, and maintenance records. The proposed framework integrates information such as facility defect identification and notification function and facility history information into standard operating procedures and establishes a BIM-based facility repair platform by combining BIM's 3D interface operation and facility equipment data utilization. The proposed framework utilized facility ID and maintenance information code in QR code format to facilitate the repair process and make the user interface more friendly. The purposes of this study are as follows:

(1) To propose the facility maintenance traceability information coding structure

(2) To propose a BIM-based facility repair platform framework

\section{Design of the Proposed BIM-Based Facility Repair Platform Framework}

The research methodology of the proposed platform is described as follows. Firstly, the information requirements of facility repair process need to be analyzed and the structure of the proposed platform are described in Section 2.1. After the completion of works above, the suitable development tool of the proposed platform and the level of development (LOD) for the standard of designing BIM need to be identified, which are described in Section 2.2. Thirdly, the structure and strategies of facility maintenance traceability information coding will be discussed in Section 2.3. Finally, the design strategy of designing the proposed facility maintenance traceability database will be discussed in Section 2.4 .

2.1. The Information Requirements and the Structure of the Proposed Platform. When a building's facility is damaged or malfunctioned and needs to be repaired, traditionally, the site FM personnel must first fill out a repair form manually in paper format. After completing the application form, it must be handed over to the manager. After the management receives the repair request order, it needs to know the correct repair needs of the report through actual visits or through contact with the repairer. After confirming the repair request, the management evaluates the current status deciding to notify the maintenance service provider to repair the update or proceed the repair work himself or not. After the completing the repair, the management unit will record the process in the existing maintenance database for the reference of the future work as shown in Figure 1.

In the proposed platform, the source of the database is the information extracted from BIM. The database also serves as an online repair report platform for users such as tenants and FM personnel. Common access is made by the web or by scanning the specific facility's QR code. Request for repair can thus be made from users' requests. Upon receiving requests, the management can check the locations, basic information, and maintenance records of the failed facilities in his/her office, so as to effectively evaluate the conditions and ensure the control of repair. As shown in Figure 2, the proposed system can enhance the effectiveness of property management. The required information of the proposed system is described as follows.

Facility basic information: the information is extracted from BIM and contains mass data, such as the equipment information provided in building, structural and MEP models, such as maintenance information and serial numbers of equipment with parameter settings. The convenience of facility information from BIM is processed by implementing the "plan" function and exported to the database of the proposed system. The display of facility locations can be done by $2 \mathrm{D}$ and $3 \mathrm{D}$ planes in the system.

Maintenance management information: the information is not got by defining the attributes of BIM's elements, such as the information related to repair service providers and repair record data. The table shown in Figure 2 supplements the maintenance management information in the system. The design of the programs takes into consideration promptness, real-time response, and convenience for users such as tenants. To make requests, the general users can use mobile devices to scan the QR codes on the facility, and the facility will immediately show the requests on the repair page in the system.

The proposed platform interface contains "repair request" and "repair progress query". Mostly, users intend to check the progress of the requests they submit; hence, these requests are distributed in the column of the repair progress query page of the system. The updates are made according to the management's feedback and track records.

After being received, the repair requests are displayed on the management's feedback page. The management first determines whether the requests shall be informed to the proper maintenance service providers. These decisions are often according to the service contract's provisions. The service providers are responsible for certain maintenance within the contract period, which will greatly reduce the subsequent repair costs. The decisions not to inform the service providers are usually made due to the following: expiration of warranty period or contract period, unable to afford the initial repair cost, or minor problems can be solved by the management. The next step is to determine 


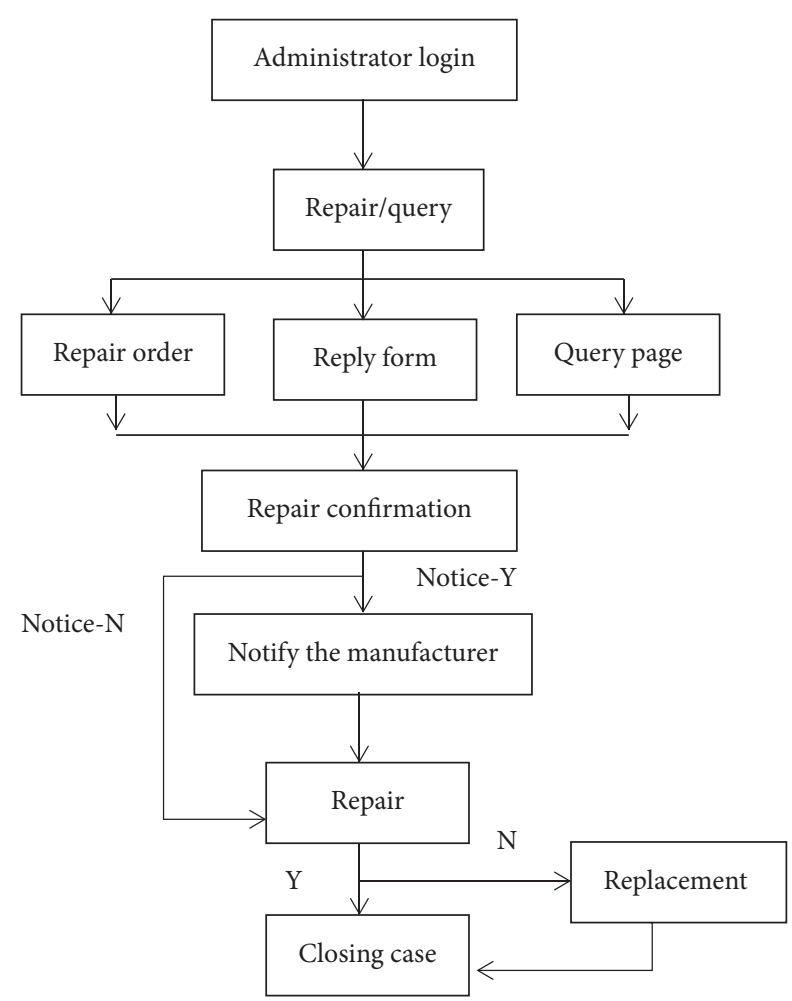

Figure 1: The conventional repair process.

whether relevant facilities can be fully repaired. If repair is practicable, it can be closed after repair, or the replacement needs to be proceeded. After the replacement is installed, this case is closed.

2.2. BIM Tools. The commonly used BIM software tools are Autodesk Revit [1], Autodesk Navisworks [20], Bentley MicroStation [3], and Graphisoft ArchiCAD [21]. Autodesk Navisworks will be used in this research.

2.2.1. Level of Development (LOD). This section discusses choosing the suitable LOD which provides the standards for establishment of the proposed platform. An inevitably problem in developing BIM is that model developers are multidisciplinary professionals who are unfamiliar with the standards. LOD provides the standards for model users to specify the detailed degree of models, and ownership of models to meet the requirements of developing BIM. LOD identifies the management responsibilities of models throughout the project phases. LOD is a BIM tool consisting of 5 progressively detailed integrity levels in E202 ${ }^{\mathrm{TM}}-2008$ of the American Institute of Architects. Based on the legal requirements of all LOD models, the 5 levels are, respectively, coded as LOD100, LOD200, LOD300, LOD400, and LOD500. After LOD is introduced, it is concluded that, in BIM, if LOD is used at the operation management stage of buildings, LOD300 is the most basic level required for this task. In other words, at the early stage of construction, BIM is implemented in building maintenance and management, because the basic information for this stage is also required for facility maintenance and management, such as actual length, width, height, location, and direction. Using LOD 100 and LOD 200 for the proposed platform is insufficient to meet the requirements of generating the information above of the facility. Although, using LOD 400 and LOD 500 is sufficient to meet the requirements above; however, the requirements of the amount of memory and disk space are also high to let the computer run more slowly. Therefore, the BIM-based proposed platform modeling used in this study is LOD300. To use the facility repair system proposed in this study, some additional information related to amenities must be added.

\subsection{Facility Maintenance Traceability Information Coding.} This section defines the facility ID code which gives the individual facility an individual identifier as a personal ID to prevent mistaken identification. Encoding is a combination of numbers, words, or letters to represent a piece of data or a narrative and by effectively classifying the user to understand the scope and meaning of the data. At present, the common coding systems can be mainly divided into tree systems, matrix systems, and layered systems, as shown in Table 1 . Therefore, if it is necessary to hand over the information processed by the computer, the concept of coding is often applied, and the narrative text or single datum is converted into a code, such as logistics management, personnel number, facility equipment number, and the like. The coding system is usually defined and generated for a certain system or project. Therefore, different systems or units cannot read other people's codes. Therefore, many public coding and coding principles are also generated, such as UniFormat in the United States. General coding scheme must follow the following principles:

(1) The coding structure should be consistent with user needs and data processing methods

(2) The code should be suitable for sorting, capturing, and excerpting of computers

(3) The code should have standard operating specifications and formats

(4) The code should be unique and standardized

(5) The coding should be simple and practical, and easy to promote

(6) The coding structure should be flexible and easy to add and expand

Coding can classify products and services for decision support. If the coding of work data can be extended, expanded, and integrated into knowledge to help measure knowledge levels and manage, appropriate coding systems can enhance the efficiency of design and construction work. According to the above, one of the most important issues in the coding system is how to maintain the coding system itself. If the code is not recognized due to it is changed by a system or unit, there is no meaning of the code. Thus, in this study, a widely used coding structure, OmniClass, is implemented in the coding standardization of the facility identification, and the specific abnormal pattern. 


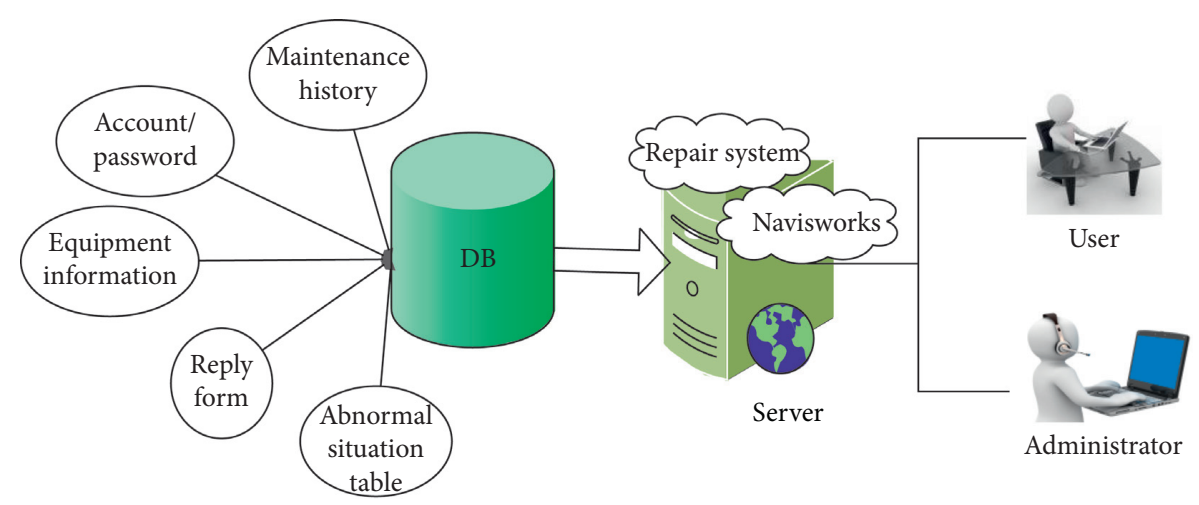

FIgURE 2: The proposed facility repair platform framework.

TABle 1: Common coding method.

\begin{tabular}{|c|c|}
\hline Coding & Description \\
\hline Sequence codes & $\begin{array}{l}\text { Sequence codes, also known as serial codes, are a continuous data system. They are given a serial code } \\
\text { according to the sequence of the number. It is simple and convenient to coding, but it cannot be } \\
\text { classified. Thus, it is difficult to produce management benefits. }\end{array}$ \\
\hline Block codes & $\begin{array}{l}\text { Objects are classified in blocks, and the same block of data uses the same code, which can distinguish a } \\
\text { block of materials with the similar characteristics. Block coding requires classification of data } \\
\text { characteristics in a tree hierarchy (for example, three layers which are large, medium, and small), and } \\
\text { each layer uses continuous coding. }\end{array}$ \\
\hline Group classification codes & $\begin{array}{l}\text { According to the characteristics of the object, it is coded in an individual or segment, and different } \\
\text { codes are given to distinguish different types. }\end{array}$ \\
\hline $\begin{array}{l}\text { Numeric coding with the specific } \\
\text { meaning }\end{array}$ & $\begin{array}{l}\text { The digits of the code represent the physical characteristics such as the size or strength of the coded } \\
\text { object. }\end{array}$ \\
\hline Ideogram coding & The coded object is represented by specific and meaningful words or numbers. \\
\hline Mixed coding & A mixture of the above coding methods. \\
\hline
\end{tabular}

The facility ID code comprises the following parts: the part 1 is designed according to the facility product ID from the OmniClass, the second part is the location identification of the facility (to ensure quick positioning), and the third part is the facilities' specific abnormal patterns. The common abnormal patterns are classified to facilitate general users to rapidly identify and select the appropriate categories in the system interface. The combinations of 3 patterns form a set of codes for identifying individual facilities, as shown in Table 2 .

The modeling tool the study implemented is Autodesk Revit. A construction classification system, Autodesk Revit, used is called OmniClass. OmniClass categorized the construction classification system into 14 categories which are construction units, space, components, work, results, products, phases, services, projects, organizational roles, tools, information, materials, and attributes. The OmniClass code is 12 digits after the coding process is completed, however, it cannot contain all the maintenance information in practice. OmniClass-compiled project numbers are used in this study, because of its comprehensiveness, and the length of codes is concise.

2.3.1. Standardized Coding of the Facility ID. OmniClass was launched by the Construction Specification Institute (CSI) in 2006. Its coding scope covers the entire life cycle of the building, including the initial planning, design, construction, and operation management stages. It connects building-related industries through coding, allows information to circulate and maintains flexibility of expansion based on project demand. OmniClass is an integrated classification system adopted in the construction industry. It has been widely applied in areas such as physical material filing or project information organization. To enrich the information used in electronic databases and software, it can also provide classification structures. Moreover, it can integrate other existing systems which are currently used as the basis of MasterFormat and UniFormat.

OmniClass provides a method for classifying the fullbuilt environment through the full-project life cycle. OmniClass intentionally includes content from all types of construction. This breadth and depth of coverage allow organizing, filtering, sorting, and retrieving information, and standardizing digital data exchanges. In addition to its use to prepare and tag project information, OmniClass consists of 15 tables, each of which represents a different facet of construction information. Each table can be used independently to classify one type of information, or entries on it can be combined with entries on other tables to further refine the classification, add more access points to the information, or classify more complex subjects. The first pair of digits designates the table number (i.e. 11, 12, 13, ..,36, 41, 
TABLE 2: Illustration of individual facility ID code.

\begin{tabular}{lcc}
\hline $082104654 \mathrm{~A}$ & 01 & A1EW1 \\
\hline The facility item ID code based on OmniClass & Abnormal pattern ID code & Location ID code \\
\hline
\end{tabular}

49). The table number digits are offset from the rest of the OmniClass number by a dash (“-”). Additional pairs of digits designate each level of classification. OmniClass describes the characteristics of objects by means of multiple sets of numbers and multiple levels. The OmniClass standardizes the construction product by 15 tables. The OmniClass also incorporates the MasterFormat into Table 2, so the two systems can refer to each other. In facility repair operations, the materials and characteristics of the facilities often result in the abnormal status and maintenance method. Thus, OmniClass is used as the facility classification coding system used in this study.

2.3.2. Coding the Facility's Abnormal Patterns. Since the study implements OmniClass for the building facilities classification coding, the coding principle for the abnormal patterns of the building facilities is the same as that of the OmniClass which uses two digits as a group. Each group of digits represents a different abnormal pattern of the building facility. The study implements windows system and doors systems as examples to investigate abnormal patterns commonly happens. The followings are the proposed code and description of common abnormal patterns of the door and window system as shown in Tables 3 and 4 [22].

Except for the abnormal type and description of the door and window system in the table above, each abnormal pattern is coded in two digits a group which is also a serial number. In OmniClass, 23.30.10.00 represents the door, and the last two digits will have different codes depending on the type or material of the door. For example, 23.30.10.00 is the general code for the door, and 23.30.10.11 is the door element. 23.30.10.11.14 is a general access door classified by material. Different digits in the layer of the code means the different classification of the door as shown in Figures 3 and 4.

In OmniClass, the basic information needs 12 digits for a complete display of the facility code. Therefore, the encoding for the abnormal pattern in this study is added after the facility code, so when the facility code is less than 12 digits, the two digits 00 are added. And after the facility code followed by the encoding of the abnormal pattern, such as the wooden door in OmniClass, is 23.30.10.14.14, a total of 10 digits, the code generated when the wooden door happens rusted will be 23.30.10.14.14.00. 01, where 01 represents the abnormal pattern code designed for this study, as shown in Figure 5.

Through the combination of the abovementioned abnormal pattern coding and facility equipment coding, the abnormal pattern of the facility can be expressed in the form of code. The proposed coding structure can simplify the maintenance traceability of each repair datum by coding and summarizing the abnormal pattern data in the repair process by the proposed coding classification system. Thus, when the
FM personnel wants to generate the maintenance strategy of the facility, he could directly query the facilities with the highest frequency of faults in the facility and identify the abnormal pattern of the fault, formulate relevant maintenance strategies based on the query results, and collect statistics of the abnormal patterns that often occur in building facilities, as shown in Figure 6.

2.3.3. Coding the Facility's Location ID. Location codes are comprised of 5 digits, which makes them short enough and easy to be quickly identified and located. The meaning of these digits is as follows:

(1) Digit 1: to identify the facility/the specific building where the facility is located.

(2) Digit 2: to identify the facility/the specific floor where the facility is located. The code $\mathrm{A}-\mathrm{Z}$ represents $1 \mathrm{~F}$ $26 \mathrm{~F}$, and the code $1-9$ represents $\mathrm{B} 1 \mathrm{~F}-\mathrm{B} 9 \mathrm{~F}$.

(3) Digit 3: to identify the specific room where the amenity is located or the followed room.

(4) Digit 4: to identify the specific location of the amenity in the room based on basic direction.

(5) Digit 5: to identify the sequence of the facilities in different types in the same room when viewed from the front (from left to right).

Combining facility item codes of the OmniClass and the location code obtains the full 15 digits serial codes.

2.4. Buildings' Facility Maintenance Traceability Database. The type of database used by the proposed system is relational database. The $3 \mathrm{D}$ models created by BIM are composed of the data in each attribute table. The attributes of the attribute table are related to each other, so the data are related. They are updated in real time, and they are also convenient for users to retrieve the information they requested. Revit Architecture and ArchiCAD are the media of BIM's information production. The selected cases of this project use Autodesk Revit to build BIM. The system of central repository is included in the Autodesk Revit-based building information model. The major function of the proposed system is to synchronously update the different requirements that different users will have on the interface of the interface, and the system provides an additional parametric design. The project will use the existing BIM combined with the external database described later to integrate the graphic and text facility traceability data as shown in Figure 3. This study uses a web-based platform to develop an information system building facility traceability. If the traditional client system is not easy to update and connect, it is more difficult to achieve the transparency and ease of use of the information required by this study. Besides, the future coding extension of the system proposed by this study is 
TABLE 3: Common abnormal patterns of the window system.

\begin{tabular}{|c|c|c|}
\hline Abnormal pattern & Code & Abnormal situation description \\
\hline Rust & 01 & $\begin{array}{l}\text { The body or accessories of the window may contain metal products, which may cause unsightly } \\
\text { appearance when rust is generated or may be inconvenient to switch when used. }\end{array}$ \\
\hline Water leakage & 02 & $\begin{array}{l}\text { Water leakage is usually caused by factors such as aging of waterproof materials, poor installation, } \\
\text { and deformation of the outer frame. When the situation is slight, the indoors are wet, and when the } \\
\text { situation is serious, the building body may be damaged due to leakage. }\end{array}$ \\
\hline $\begin{array}{l}\text { Water-repellent material } \\
\text { shedding }\end{array}$ & 03 & Water-repellent material shedding is usually caused by factors such as aging or improper use \\
\hline Glass rupture & 04 & $\begin{array}{l}\text { Glass rupture is usually caused by external factors, which may cause personal injury. In this case, new } \\
\text { products need to be replaced. If it is a special glass, it must be contacted by the manufacturer for } \\
\text { replacement. }\end{array}$ \\
\hline Window frame deformation & 05 & $\begin{array}{l}\text { Possible reasons for the deformation of the window frame include poor material quality, improper } \\
\text { gap filling, and external force effects, which may result in poor window adhesion and inconvenient } \\
\text { switch. }\end{array}$ \\
\hline Screw rust & 06 & $\begin{array}{l}\text { The long-term exposure of the screw to air or humid environment is prone to chemical reactions and } \\
\text { gradually loses its fixed function for a long time, which is likely to cause damage to the window. }\end{array}$ \\
\hline $\begin{array}{l}\text { The damage of window- } \\
\text { sliding lock }\end{array}$ & 07 & The damage of window-sliding lock results from improper use or aging \\
\hline $\begin{array}{l}\text { The damage of screen } \\
\text { window }\end{array}$ & 08 & The damage of the screen window or its frame results from improper use or aging \\
\hline
\end{tabular}

TABle 4: Common abnormal patterns of the door system.

\begin{tabular}{|c|c|c|}
\hline Abnormal pattern & Code & Abnormal situation description \\
\hline Rust & 01 & $\begin{array}{l}\text { The body or accessories of the door may contain metal products, which may cause unsightly } \\
\text { appearance when rust is generated or may be inconvenient to switch when used. }\end{array}$ \\
\hline Water leakage & 02 & $\begin{array}{l}\text { Water leakage is usually caused by factors such as aging of waterproof materials, poor installation, and } \\
\text { deformation of the outer frame. When the situation is slight, the indoors are wet, and when the } \\
\text { situation is serious, the building body may be damaged due to leakage. }\end{array}$ \\
\hline $\begin{array}{l}\text { Water-repellent material } \\
\text { shedding }\end{array}$ & 03 & Water-repellent material shedding is usually caused by factors such as aging or improper use \\
\hline Glass rupture & 04 & $\begin{array}{l}\text { Glass rupture is usually caused by external factors, which may cause personal injury. In this case, new } \\
\text { products need to be replaced. If it is a special glass, it must be contacted by the manufacturer for } \\
\text { replacement. }\end{array}$ \\
\hline The damage of door handle & 05 & The damage of door handle results from improper use \\
\hline The damage of door lock & 05 & The damage of door lock results from improper use \\
\hline Screw rust & 07 & $\begin{array}{l}\text { The long-term exposure of the screw to air or humid environment is prone to chemical reactions and } \\
\text { gradually loses its fixed function for a long time, which is likely to cause damage to the window. }\end{array}$ \\
\hline Door frame deformation & 08 & $\begin{array}{l}\text { Possible reasons for the deformation of the door frame include poor material quality, improper gap } \\
\text { filling, and external force effects, which may result in poor door adhesion and inconvenient switch. }\end{array}$ \\
\hline The damage of door leaf & 09 & The damage of door leaf is mostly caused by external force, such as broken and corroded. \\
\hline The damage of roll-up door & 10 & $\begin{array}{c}\text { The damage of roll-up door is mostly due to external forces, causing the roll door not to function } \\
\text { properly }\end{array}$ \\
\hline The damage of hinge & 11 & The damage of hinge results from aging \\
\hline $\begin{array}{l}\text { The damage of door } \\
\text { operator }\end{array}$ & 12 & $\begin{array}{l}\text { The door operator acts as a buffer of the door leaf, and its damage is usually accompanied by damage } \\
\text { to the door leaf or other accessories. }\end{array}$ \\
\hline
\end{tabular}

easier to manage and update than the traditional client system.

In the design of the early client server system, each application must be installed on each user's personal computer. When the system is upgraded, it must be connected to the server. Usually, this process will increase the cost and reduce the efficiency. The device traceability information module of the proposed system is written in
$\mathrm{XML}$, and its biggest advantage is that it can communicate with cross-platform data. When managers write device traceability information modules in XML, they can still display information and freely definable tags through a browser. The tag in XML has no meaning, so the user can define the tag by any name. The user can provide information and parameters to the browser's computing module or plug in to process the file. The web-based platform 


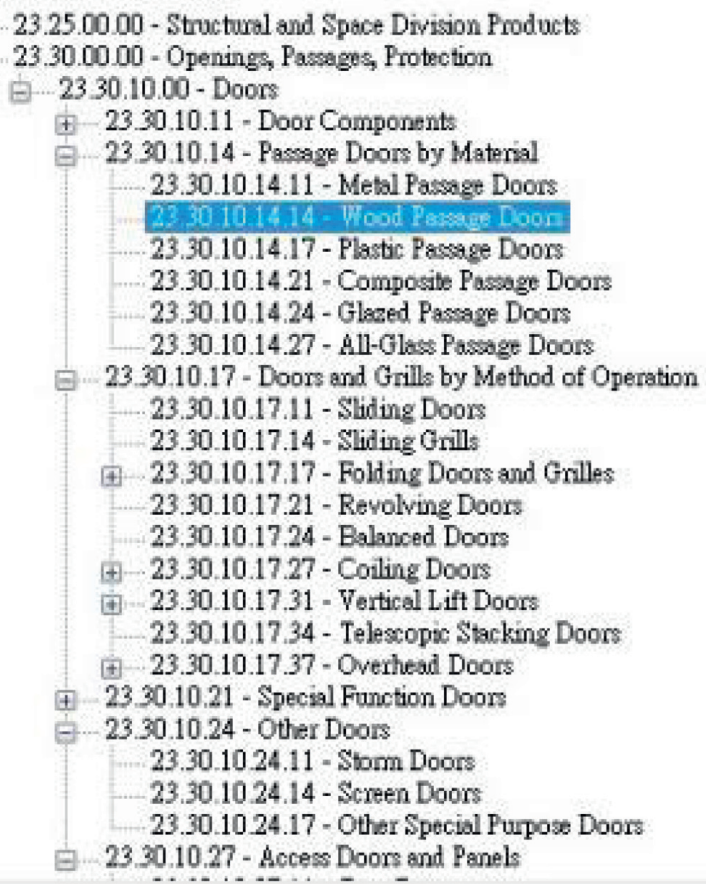

Figure 3: The door system coding in OmniClass (source: Autodesk Revit 2016) [20].

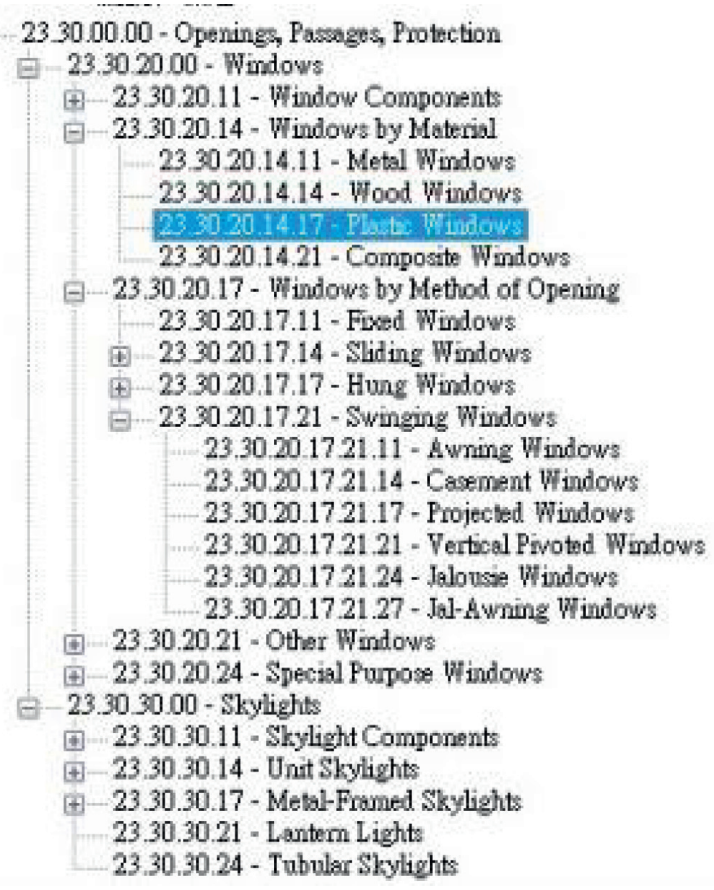

FIgure 4: The window system coding in OmniClass (source: Autodesk Revit 2016) [20].

proposed by the study is an application executed in a browser. The user interface is written on a server in a web page format. After the completion of the facility traceability

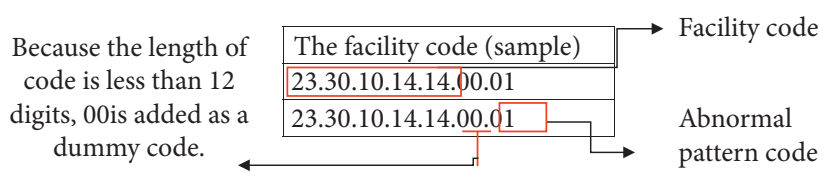

Figure 5: The sample of the proposed facility code.

information code, the system administrators code the facility traceability data according to the coding structure proposed by the Institute. One code represents a facility traceability data. The facility or equipment in a specific space will be assigned a separate code in the facility traceability database because of its uniqueness. Considering the convenience, immediacy, and practicality of users browsing the facility traceability data, this study combines this system with the Smart Handheld Device application, as shown in Figure 7.

\section{A Case Test}

To verify the feasibility of the proposed system, this research presents a case test and the case is a two-story villa with a basement level. BIM has been achieved at the stage of design (Figure 8). The living room of the first floor in the case has a window was selected as a case sample to request for repair. The user could scan the QR code attached on the specific facility to access the proposed system. After entering the proposed system, the user could make a request for repair and select the facility for this task. The tenant could enter a serial number or by specifying its building, floor, and room through a dropdown list. The user could select the specific window when locating the room. After that, the request form page is shown in Figure 8. Users could also open the floor plan from BIM and select the specific items when selecting the floor.

In a repair for request form, the user could manually enter a brief description about the conditions and then submit the request. After that, users could check the repair status using query function. Upon receipt of the request, FM staffs receive the feedback (Table 5) alarm and briefly introduce the situation. By clicking the location button on the repair for the request form, the management could identify the problem by accessing BIM (Figure 9).

The information on the proposed repair order is generated from the following: the facility equipment traceability, maintenance traceability, abnormal status data, and note description. The facility equipment traceability data are the basic information of the facility, followed by the maintenance traceability data, which are automatically generated from the database; the abnormal status data are the type of abnormal conditions that may occur in the equipment, and the operator can check the abnormal status of the proposed repair order or 


\begin{tabular}{|c|c|c|c|c|c|c|c|c|c|c|c|c|c|c|}
\hline & $\mathrm{NO}$ & DATA & adm, & Code & Type & location & \begin{tabular}{|l} 
Abnormal \\
state \\
\end{tabular} & $\begin{array}{l}\text { Abnormal } \\
\text { state code }\end{array}$ & remark & $\begin{array}{l}\text { Maintenance } \\
\text { vendor }\end{array}$ & $\begin{array}{l}\text { Maintenance } \\
\text { progless }\end{array}$ & \begin{tabular}{|l|} 
Report \\
confirmation
\end{tabular} & $\begin{array}{l}\text { Repair } \\
\text { confirmation }\end{array}$ & $\begin{array}{l}\text { Completion } \\
\text { of the case }\end{array}$ \\
\hline Ed't & 7 & 2016.05 .08 & 01 & \begin{tabular}{|l|} 
23.30.10.14.14 \\
-A1051
\end{tabular} & Wo921 & loce & $\begin{array}{l}\text { Dimmsed } \\
\text { handle }\end{array}$ & 01.02 .04 & & O00:company & $\begin{array}{l}\text { Reporting } \\
\text { demend } \\
\text { confirmation }\end{array}$ & 0 & 0 & 0 \\
\hline
\end{tabular}

FIgURE 6: Request for repair from the web page.
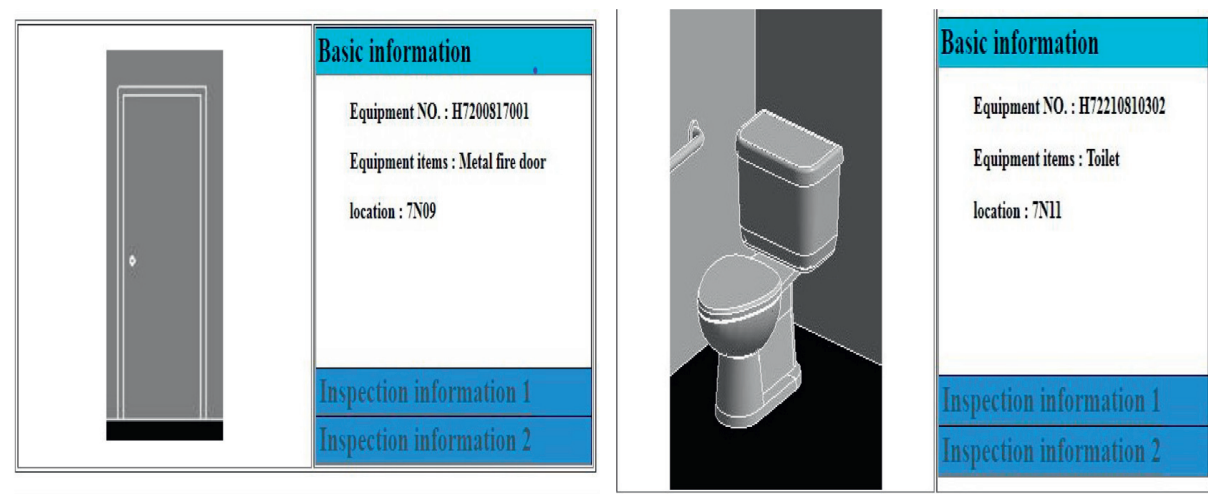

FIGURE 7: The sample menu of the facility's traceability information.

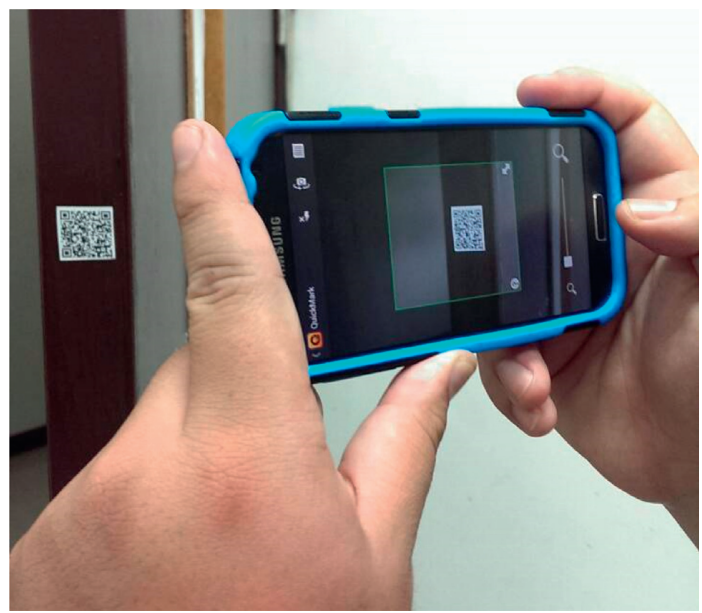

FIGURE 8: Scanning QR code by a mobile device.

TABLE 5: Repair/maintenance traceability.

Facility basic information

Amenity/facility code

Building

Maintenance information

Years of use

Maintain the manufacturer
08510RK02A-AAGE2

A

20

AA
Type

Floor

Last maintenance date Repair status
$\mathrm{C} 0823$

$1 \mathrm{~F}$

$2017 / 02 / 07$

Repair confirmation leave a message to the management unit, as shown in Figure 10.

After the site FM personnel verified the request information, firstly, he will evaluate whether to contact with relevant service providers to seek for further assistance or to repair the damages himself. In addition, the repair progress can be controlled via the feedback page of the system (synchronizing with the query page), so as to initiate the tenant access progress updates (Figure 11). 


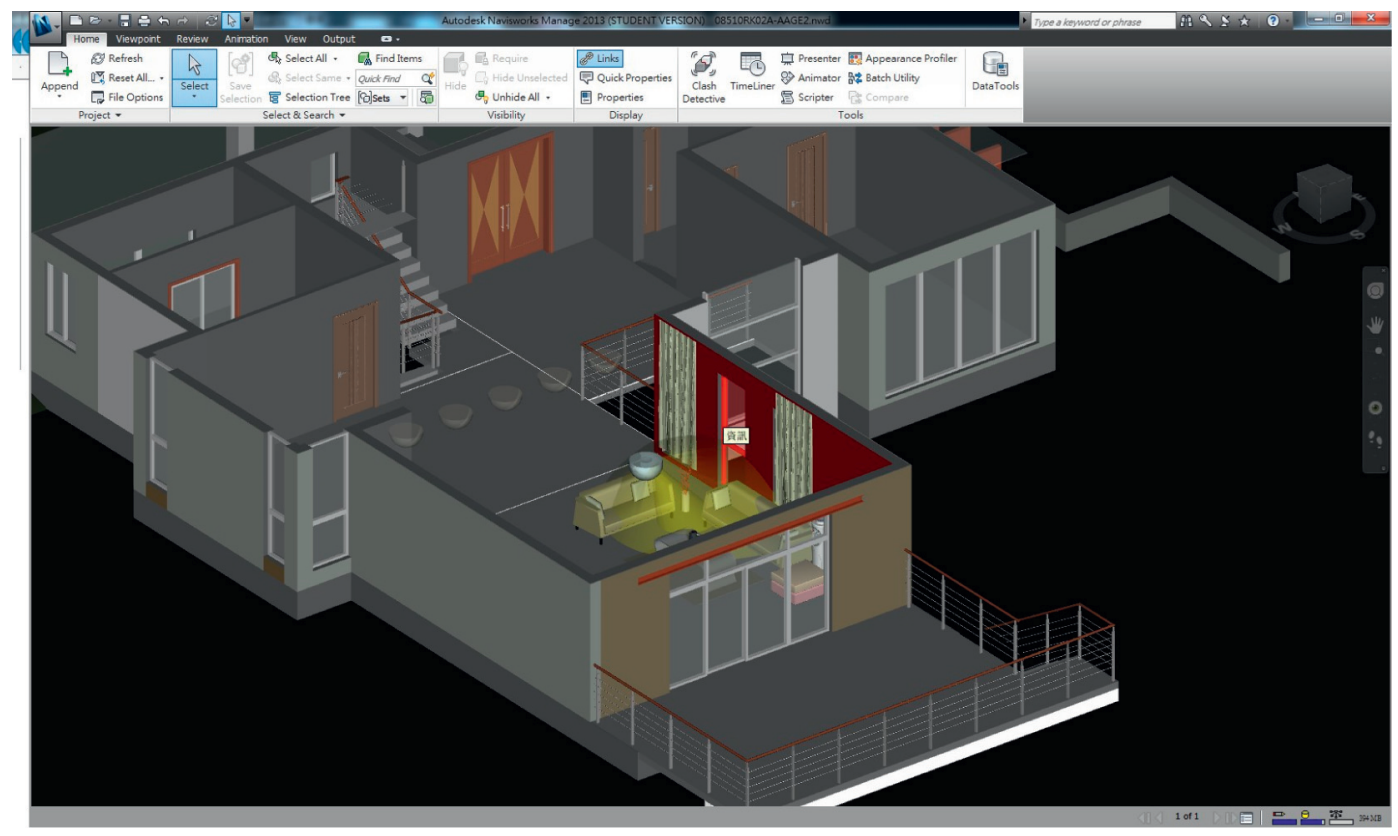

FIgURE 9: The illustration of the facility's location from BIM.

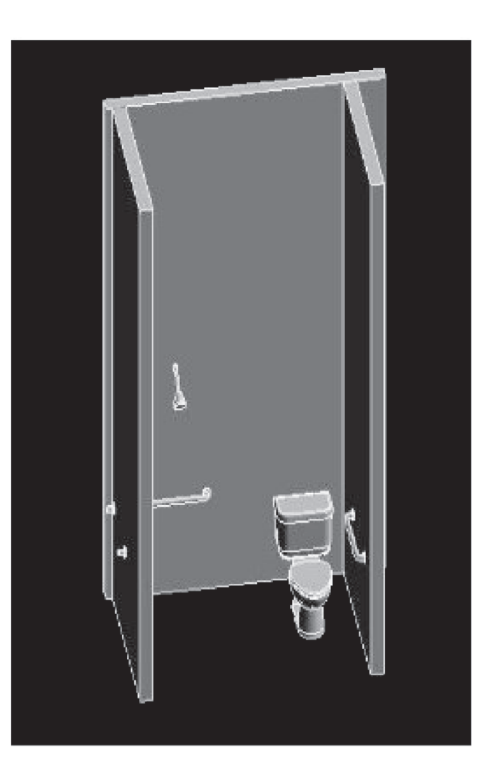

\begin{tabular}{|c|c|c|c|}
\hline \multicolumn{4}{|c|}{ Facility basic information } \\
\hline \begin{tabular}{|l|} 
Numbering \\
\end{tabular} & 10801001-H720 & type & Toilet cubicle \\
\hline Building & Huwei -H & floor & $7 \mathrm{~N} 09(720)$ \\
\hline \multicolumn{4}{|c|}{ Maintenance history } \\
\hline $\begin{array}{c}\text { Purchase } \\
\text { date }\end{array}$ & 2016/3/18 & $\begin{array}{c}\text { Inspection } \\
\text { date }\end{array}$ & $2017 / 3 / 15$ \\
\hline \begin{tabular}{|c|}
$\begin{array}{c}\text { Maintenance } \\
\text { vendor }\end{array}$ \\
\end{tabular} & Zheng-Tai & administrator & Camp group \\
\hline \multicolumn{4}{|c|}{ Abnormal condition } \\
\hline \multicolumn{2}{|r|}{ item } & \multicolumn{2}{|r|}{ item } \\
\hline$\square$ & Corrosion & $\square$ & Leaking water \\
\hline$\square$ & $\begin{array}{l}\text { Waterproof material } \\
\text { falling off }\end{array}$ & $\square$ & Glass rupture \\
\hline $\bar{\square}$ & Damage to accessories & $\bar{\square}$ & Door leaf damage \\
\hline $\bar{\square}$ & Loose & $\bar{\square}$ & Door frame deformation \\
\hline$\square$ & Gambling & $\square$ & Abnormal water quality \\
\hline$\square$ & $\begin{array}{l}\text { Abnormal water } \\
\text { pressure }\end{array}$ & $\square$ & Breakage fracture \\
\hline$\square$ & $\begin{array}{l}\text { Abnormal power } \\
\text { supply }\end{array}$ & $\square$ & Cracking \\
\hline
\end{tabular}

FIGURE 10: Illustration of the facility's abnormal patterns for repair menu page.

\begin{tabular}{|c|c|c|c|c|c|c|c|c|c|c|c|c|c|}
\hline & N10. & DHTA & \begin{tabular}{|l|}
$\mathrm{d} m \mathrm{~m}$. \\
\end{tabular} & Code & Type & location & \begin{tabular}{|l|}
$\begin{array}{l}\text { Abnomal } \\
\text { state }\end{array}$ \\
state
\end{tabular} & remark & $\begin{array}{l}\begin{array}{l}\text { Maintenance } \\
\text { vendor }\end{array} \\
\text { late }\end{array}$ & $\begin{array}{l}\text { Mainterance } \\
\text { progeges }\end{array}$ & \begin{tabular}{|l} 
Report \\
confimstion \\
\end{tabular} & $\begin{array}{l}\text { Repair } \\
\text { confirmation }\end{array}$ & $\begin{array}{l}\text { Completion } \\
\text { of the case }\end{array}$ \\
\hline Edit & 7 & 20150508 & 01 & $\begin{array}{l}0821045544 \\
.4851\end{array}$ & 10021 & loca & $\begin{array}{l}\text { Corresion } \\
\text { Damagas } \\
\text { herdla }\end{array}$ & & 000owsany & $\begin{array}{l}\text { Rapir } \\
\text { owoplated }\end{array}$ & 0 & 0 & D \\
\hline Edit & 8 & 201605.14 & 01 & $\begin{array}{l}0831120004 \\
\text { ALWI }\end{array}$ & JUSG422 & loca & $\begin{array}{l}\text { Hinged } \\
\text { derage }\end{array}$ & & AM comprey & - & 0 & 0 & [ \\
\hline Edit & 9 & 201605.18 & 02 & $\begin{array}{l}055106024 \\
\text { HG52 }\end{array}$ & coses & loca & \begin{tabular}{|l|} 
Glass \\
rupture
\end{tabular} & & ceompany & $\begin{array}{l}\text { Repporting } \\
\text { demand } \\
\text { costimetion }\end{array}$ & 0 & 0 & 0 \\
\hline Edit & 10 & 201606008 & 01 & $\begin{array}{l}\text { O555106024 } \\
\text { AGG2 }\end{array}$ & 00823 & locea & \begin{tabular}{|l}
$\begin{array}{l}\text { Leaking } \\
\text { watter }\end{array}$ \\
\end{tabular} & $\begin{array}{l}\text { Bottom } \\
\text { mappage }\end{array}$ & Do compry & $\begin{array}{l}\text { Reporting } \\
\text { demend } \\
\text { confimention }\end{array}$ & 0 & 0 & 0 \\
\hline
\end{tabular}

FIGURE 11: Illustration of request for repair menu page. 


\section{Conclusions and Suggestions}

This study proposes the facility maintenance traceability information coding structure and proposes a BIM-based facility repair platform framework. This study also verifies the feasibility of the proposed approach with a case study. The findings and suggestions of this study are described as follows:

(1) The required information types of the proposed system are identified which include facility basic information extracted from BIM and maintenance management information from repair service providers and repair record data. Above information is needed for the platform application uses.

(2) The proposed method presents a facility traceability coding structure which is a combination of the OmniClass, abnormal pattern ID code, and location ID code. OmniClass is used for the different facility identification. Abnormal pattern ID code is the different type of defect identification which can simplify the maintenance traceability of each repair datum by coding and summarizing the abnormal pattern data in the repair process. Location codes make FM easy to quickly identify and locate the facility needed to be repaired. The proposed facility traceability coding structure can facilitate the FM information transfer among stakeholders. Through the case test's finding, the proposed facility code in QR code format can help users and FM personnel identify and locate the specific or abnormal facility with QR code quickly.

(3) This proposed platform is aimed to be integrated into the facility maintenance system after completion of construction, so the as-built drawing is required, so as to be consistent with the drawings and information of the field equipment and BIM. The proposed platform is an online repair report system for users such as tenants and FM. Common access can be made by the web or by scanning the specific facility's QR code from the proposed facility maintenance information coding. Upon receiving request for repair, the FM can check the locations, basic information, and maintenance records of the failed facilities from users' mobile device, so as to effectively evaluate the conditions and ensure the control of repair of the facility. From the case study, the proposed platform enables FM personnel to generate the request for repair from the proposed platform which can also link to the historical data of the facility and help FM personnel make preliminary facility repair judgments and schedule maintenance plan to track the status of the facility repair from the traceability database. The proposed BIM-based platform provides a visual display user interface that let FM personnel locate facilities for needed repair quickly. The proposed approach can help improve the efficiency of facility management and simplify the repair process.
(4) Although the proposed platform in the study is not to be equipped with the function of machine learning so far, however, through the proposed database, the objective of machine learning can be achieved with enough experience learning, knowledgebase, and the related artificial intelligent (AI) algorithm module in the future study.

\section{Data Availability}

No data were used to support this study.

\section{Conflicts of Interest}

There are no conflicts of interest regarding the publication of this paper.

\section{References}

[1] Autodesk Revit: http://www.autodesk.com/products/autodeskrevit-family/overview.

[2] A. Mahadi and H. Hussin, Pengurusan Aset Kerajaan Berkomputer: Satu Anjakan Paradigma, http://www.audit.gov.my/ docs/BM/6Penerbitan/2Buletin Audit/4.BuletinBil4DIS07.pdf, 2007.

[3] Bentley MicroStation, http://www.bentley.com/zh-TW/.

[4] H. Kim, K. Anderson, S. Lee, and J. Hildreth, "Generating construction schedules through automatic data extraction using open BIM (building information modeling) technology," Automation in Construction, vol. 35, pp. 285-295, 2013.

[5] T. Tamada, Y. Nakamura, and S. Takeda, "An efficient 3D object management and interactive walkthrough for the 3D facility management system," in Proceedings of the IECON'94 20th Annual Conference of IEEE Industrial Electronics, vol. 3, pp. 1937-1941, Bologna, Italy, September 1994.

[6] A. Akcamete, B. Akinci, and J. H. Garrett, "Potential utilization of building information models for planning maintenance activities," in Proceedings of the International Conference on Computing in Civil and Building Engineering, W. Tizani, Ed., p. 151, Nottingham, UK, 2010.

[7] A. Motamedi, A. Hammad, and Y. Asen, "Knowledge-assisted BIM-based visual analytics for failure root cause detection in facilities management," Automation in Construction, vol. 43, pp. 73-83.

[8] R. Liu and R. R. A. Issa, "BIM for facility management: Design for maintainability with Bim tools," in Proceedings of the 30th International Symposium on Automation and Robotics in Construction and Mining (ISARC 2013): Building the Future in Automation and Robotics, pp. 321-328, Montréal, Canada, 2013.

[9] J.-H. Lee, M.-S. Lee, S.-H. Lee et al., "Development of computerized facility maintenance management system based on reliability centered maintenance and automated data gathering," International Journal of Control and Automation, SERSC, vol. 6, no. 1, pp. 1-12, 2013.

[10] E. Mozaffari, A. Hammad, and K. El-Ammari, "Virtual reality models for location-based facilities management systems," in Proceedings of the 1st CSCE Specialty Conference on Infrastructure Technologies, Management and Policy, Toronto, Ontario, Canada, June 2005.

[11] H.-M. Chen, C.-C. Hou, and Y.-H. Wang, "A 3D visualized expert system for maintenance and management of existing building facilities using reliability-based method," Expert Systems with Applications, vol. 40, no. 1, pp. 287-299, 2013. 
[12] B. Becerik-Gerber, F. Jazizadeh, N. Li, and G. Calis, "Application areas and data requirements for BIM-enabled facilities management," Journal of Construction Engineering and Management, vol. 138, no. 3, pp. 431-442, 2012.

[13] J. J. McArthur, "A building information management (BIM) framework and supporting case study for existing building operations, maintenance and sustainability," Procedia Engineering, vol. 118, pp. 1104-1111, 2015.

[14] T. W. Kang and C. H. Hong, "A study on software architecture for effective BIM/GIS-based facility management data integration," Automation in Construction, vol. 54, pp. 25-38, 2015.

[15] H. Kim, Z. Shen, I. Kim, K. Kim, A. Stumpf, and J. Yu, "BIM IFC information mapping to building energy analysis (BEA) model with manually extended material information," $A u$ tomation in Construction, vol. 68, pp. 183-193, 2016.

[16] M. Laaksoand and L. Nyman, "Exploring the relationship between research and BIM standardization: a systematic mapping of early studies on the IFC standard (1997-2007)," Buildings, vol. 6, no. 1, pp. 1-7, 2016.

[17] H. Hamledari, E. R. Azar, and B. McCabe, "IFC-based development of as-built and as-is BIMs using construction and facility inspection data: site-to-BIM data transfer automation," Journal of Computing in Civil Engineering, vol. 32, no. 2, Article ID 04017075, 2018.

[18] B. East, Construction Operations Building Information Exchange (COBie), NIBS, Delhi, India, 2014.

[19] L. Zhang and L. Dong, "Application study on building information model (BIM) standardization of Chinese engineering breakdown structure (EBS) coding in life cycle management processes," Advances in Civil Engineering, vol. 2019, pp. 1-10, 2019.

[20] Autodesk Navisworks: http://www.autodesk.com/products/ autodesk-navisworks-family/overview.

[21] Graphisoft ArchiCAD, http://www.graphisoft.com/archicad/.

[22] A. Straub, "Maintenance and repair," International Encyclopedia of Housing and Home, vol. 4, pp. p186-194, 2012. 